\title{
An evaluation of effect of airborne dust from a cotton mill on the guinea-pig ileum with reference to byssinosis ${ }^{1}$
}

\author{
F. F. CINKOTAI and D. W. FRANKLIN \\ Department of Occupational Health, University of Manchester, Stopford Building, \\ Oxford Road, Manchester M13 9PT
}

\begin{abstract}
Cinkotai, F. F. and Franklin, D. W. (1975). British Journal of Industrial Medicine, 32, 239-243. An evaluation of the effect of airborne dust from a cotton mill on the guinea-pig ileum with reference to byssinosis. The effect of airborne dust on the guinea-pig ileum was studied. Tyrode extracts of airborne dust collected freshly in the cardroom of a cotton mill, and extracts of air pollutant samples drawn on the roof of the mill and of the local town hall were all found to induce the guinea-pig ileum to contract when applied in a tissue-bath. However, the force of contraction with air pollutants was rather greater than that with the cardroom dust. Considering the variables involved, the ileum response to the cardroom dust may have been due to ordinary air pollutants which constitute a significant part of the dust. It is concluded that this pharmacological phenomenon is probably not relevant in the context of byssinosis.
\end{abstract}

Davenport and Paton (1962), and Nicholls (1962) have shown that aqueous extracts of cotton mill dust cause smooth muscles such as guinea-pig ileum and trachea, rat stomach strip and duodenum, and human bronchial muscles to contract. It has been suggested that this activity of the dust is possibly linked with its pathogenic property to bring about byssinosis and may be a useful index of the pathogenicity of the dust. Recently however, Berry et al. (1973) found that extracts of airborne dust drawn from a mill processing man-made fibre affect the guinea-pig ileum nearly as much as do those of cotton mill dust, suggesting that this pharmacological activity may not be relevant to the aetiology of byssinosis. The study presented here has been initially undertaken to evaluate the effect of airborne dust on the guinea-pig ileum as a possible test of the capacity of the dust to induce byssinosis.

1This work was financed from the Cotton Grower's Association Fund.

\section{Procedure}

Sampling of airborne dust

Dust samples were obtained from one of the coarse cotton mills of Courtaulds Limited at Shaw, Lancashire. The samples were drawn at $1.5 \mathrm{~m}$ height in the centre of the floor of a shop occupied by 30 high-speed cards, eight tandem cards, and numerous draw-frames and speed-frames. The carding machines were fitted with Shirley Pressure Point System dust control equipment. Air pollution samples were obtained on the roof of the mill as well as on the roof of Shaw Town Hall half a mile away. Sampling was carried out by means of a portable dust sampler (Rotheroe and Mitchell Ltd., model L60) and a seven-stage cascade impactor (Sciotec Corporation, USA, model CS-1-6A). The Rotheroe and Mitchell sampler collected total dust less 'fly' and consisted simply of a pump and filter capable of sampling the atmosphere at the rate of 60 litres per minute. The sampling head was placed into a $22 \mathrm{~cm} \times 27 \mathrm{~cm}$ cage made of wire gauze with a $2 \mathrm{~mm}$ mesh to exclude fly.

The cascade impactor sampled at the rate of 12.7 litres per minute. The particles sampled were deposited according to size (Stoke's diameter) on six circular plates 
smeared lightly with Vaseline and a glass-fibre filter. Plate 1 collected mostly the particles with aerodynamic diameter greater than $16 \mu \mathrm{m}$; plate 2collected the 8 to $16 \mu \mathrm{m}$ particles; plate 3,4 to $8 \mu \mathrm{m}$; plate 4,2 to $4 \mu \mathrm{m}$; plate 5 , 1 to $2 \mu \mathrm{m}$; plate $6,0.5$ to $1 \mu \mathrm{m}$; and the filter collected the particles smaller than $0.5 \mu \mathrm{m}$. The air sample was drawn through a wire gauze of $2 \mathrm{~mm}$ mesh to exclude fly. Particles on the various plates were examined under light and scanning electron microscopes.

\section{Extraction of dust samples with Tyrode solution}

In preparation for the guinea-pig ileum test the dust samples were extracted with Tyrode solution. The Rotheroe Mitchell samples (total dust less fly) together with the glass-fibre paper carrier were ground for 15 minutes with acid-washed sand and Tyrode solution in a ceramic pestle and mortar. The suspension was centrifuged and the supernatant extract was used for testing. The extract solution was characterized by the ratio of the weight of dust to the volume of Tyrode solution $(\mathrm{mg} / \mathrm{ml})$ used. The cascade impactor samples collected on Vaseline layers were in some instances washed before extraction with petroleum ether to remove the Vaseline and in others the sample and Vaseline were extracted together. A control solution was prepared with each test solution.

\section{Measurement of effect of dust extracts on guinea-pig ileum under tension}

A piece of guinea-pig ileum about 1-2 $\mathrm{cm}$ long was prepared freshly as described before (Department of Pharmacology, University of Edinburgh, 1970). One end of the ileum was tied to a glass hook with cotton thread and was lowered into a tissue bath of 2 or $10 \mathrm{ml}$ in volume containing aerated Tyrode solution. The other end was then tied to a strain gauge and the tension in the ileum was set at $500 \mathrm{mg}$ by raising the gauge on the rack. The output of the strain gauge was recorded on a penrecorder. The temperature of the bath was maintained at $37^{\circ} \mathrm{C}$ by circulating water in its jacket from a water tank regulated at that temperature. Measured doses of the test solution were either added to the Tyrode solution in the bath or dripped down the ileum preparation with the bath empty, as described by Gaddum (1953). Resultant changes in the ileum tension were sensed by the strain gauge and recorded on the pen-recorder, the deflections on which were calibrated in milligrams. Between measurements the preparation was twice washed by emptying and immediately refilling the bath from a reservoir of Tyrode solution kept at $37^{\circ} \mathrm{C}$.

Before the dust extracts were tested, the contraction of the ileum preparation was calibrated with histamine acid phosphate (HAP) solution added to the Tyrode solution in the bath or dripped down the preparation with the bath empty, as was appropriate. The HAP concentrations applied to the ilea ranged between $2 \mathrm{ng} / \mathrm{ml}$ and $200 \mathrm{ng} / \mathrm{ml}$. A curve of HAP concentration $(\mathrm{ng} / \mathrm{ml})$ versus ileum response (percentage of maximum) was plotted for each preparation. The sensitivity of the preparation was characterized by the HAP concentration that induced $50 \%$ of the maximum tension $\left(\mathrm{HD}_{50} \%\right)$. On the basis of the calibration curves the dust extract responses (contractions) were adjusted for differing ileum sensitivities by expressing the tension changes ( $\Delta \mathrm{F})$ in terms of HAP concentrations which would have induced the changes, and finding the tension changes $\left(\Delta F_{S}\right)$ that these concentrations would have caused on a typical ileum preparation (with a sensitivity of $140 \mathrm{ng} / \mathrm{ml} \mathrm{HD}_{50} \%$ ). The tension changes per $10 \mathrm{mg} / \mathrm{ml}$ dust concentration were approximately calculated by adding the term 1350 $\left(1-\log _{10} \mathrm{C}\right)$ to the response. In doing so, the concentration (C)-response $(\Delta \mathrm{F})$ relationship was taken to be $\Delta \mathrm{F}=$ $1350\left(1+\log _{10} C\right)$, which in fact is a rough approximation of the actual curve. No adjustments were made in cases of ileum relaxation.

\section{Results}

\section{Microscopy of the impactor fractions}

The results of the examination of dust samples under light and scanning electron microscopes did not basically differ from those of earlier investigators. Cotton fibres were seen on plates 1,2 , and 3 , plant fragments and vegetable debris probably on all plates, mineral particles on plates 3 and 4 , spheres and possible fragments of fungal colonies on plates 4, 5 (Fig. 1), and 6, and pollution particles on plates 5 and 6 . Many particles on plates 4, 5, and 6 appeared to be greater than $10 \mu \mathrm{m}$ in diameter. Culture studies indicated that many of the spheres were fungal spores. Viable bacteria were not detected but bacterial spores were.

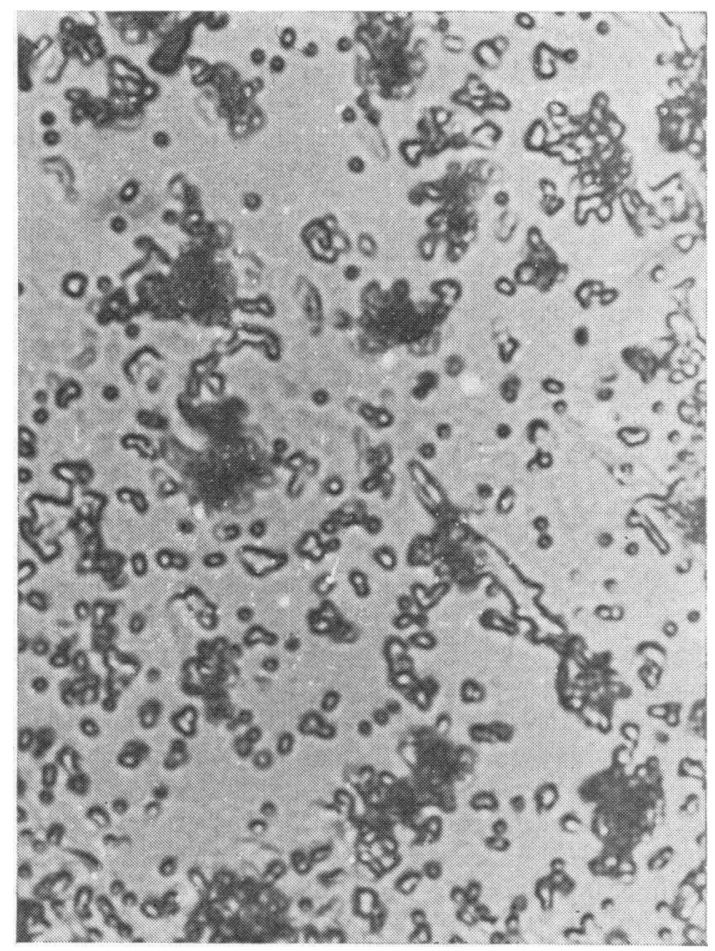

FIG. 1. An electron micrograph of particles collected on plate 5 of the cascade impactor $(\times 1000)$. 
TABLE 1

Response of Ileum Preparations to Tyrode and Histamine Acid Phosphate (HAP) Solutions

\begin{tabular}{l|c|c|c|c}
\hline \multicolumn{1}{c|}{ Solution applied } & $\begin{array}{c}\text { Number of } \\
\text { guinea-pigs }\end{array}$ & $\begin{array}{c}\text { Number of } \\
\text { measurements }\end{array}$ & $\begin{array}{c}\text { Average } \\
\text { response (mg) }\end{array}$ & $\begin{array}{c}\text { Range } \\
\text { (min. value-max. } \\
\text { value in mg) }\end{array}$ \\
\hline Tyrode & 1 & 9 & 20 & -30 to +60 \\
& 14 & 36 & 11 & -30 to +70 \\
HAP solution 10 ng/ml & 1 & 20 & 1300 & $1030-1660$ \\
& 20 & $760-1780$ & 3040 & $2750-3250$ \\
HAP solution inducing maximum \\
tension
\end{tabular}

Stability and sensitivity of the ileum preparations used The ileum preparations were found to respond to Tyrode solution with a small tension change of -30 $\mathrm{mg}$ to $+60 \mathrm{mg}$ force (Table 1 ). When $10 \mathrm{ng} / \mathrm{ml}$ HAP solution was applied in a $2-\mathrm{ml}$ bath, as was usually the case, the ileum taken from one guinea-pig contracted with a force of $100 \mathrm{mg}$ to $1660 \mathrm{mg}$ and the ilea from 20 others with $360 \mathrm{mg}$ to $1780 \mathrm{mg}$ (Table 1). A contraction with $2750 \mathrm{mg}$ force was on average the maximum with these preparations. The sensitivity of the preparation to histamine solutions depended to some extent on whether the solution was added to the organ bath containing the Tyrode solution or was dripped down the preparation (superfused) with the bath empty. Curves of HAP concentration $(\mathrm{ng} / \mathrm{ml})$ versus ileum response (as a percentage of maximum) with histamine solutions added to the Tyrode baths or superfused are shown (Fig. 2).

Effect of dust extracts and control solutions on ileum preparations

The Tyrode extracts of cardroom dust in $1 \mathrm{mg} / \mathrm{ml}$



FIG. 2. The dose-response relationship for histamine acid phosphate (HAP) solutions on guinea-pig ileum. to $10 \mathrm{mg} / \mathrm{ml}$ concentrations caused the ileum preparations to contract on average with $1256 \mathrm{mg}$ force and the control solutions with $201 \mathrm{mg}$ (Table 2). Extracts of the outside dust from the roof of the mill and the local town hall in $5 \mathrm{mg} / \mathrm{ml}$ to $10 \mathrm{mg} / \mathrm{ml}$ concentrations brought about on average a contraction of $1518 \mathrm{mg}$, and the corresponding controls $106 \mathrm{mg}$. When the responses were expressed as those of a standard ileum (with $\mathrm{HD}_{50 \%}=140 \mathrm{ng} / \mathrm{ml}$ ) per $10 \mathrm{mg} / \mathrm{ml}$ dust concentration, the above average became $1370 \mathrm{mg}$ for the cardroom dust and 2131 mg for the outside dust.

The extracts of old cardroom dust (Table 3) that was kept standing for 160 to 185 days aftercollection but before extraction and a further 1 to 42 days before testing caused the ileum to relax from its base tension of $500 \mathrm{mg}$ on average by $186 \mathrm{mg}(\Delta \mathrm{F}=$ $-186 \mathrm{mg}$ ). The corresponding controls induced on average a contraction of $15 \mathrm{mg}$ force (Table 3). Tests on the impactor fractions were inconclusive.

\section{Discussion}

The abundance of regular spheres on the lower impaction plates as revealed by microscopy was striking (Fig. 1). They were probably mostly fungal spores, and judging from the weights of the fractions they may have contributed up to $15 \%$ of the total airborne mass sampled. The apparently large particles observed in these fractions had low aerodynamical diameter, probably because of light sponge-like structure. These may have been plant debris or fragments of fungal colonies.

As the size of the dust samples was restricted by the capacity of our sampling instruments, the number of ileum tests carried out had to be kept to a minimum. Because of this and because of the rather high variability of ileum response the dust extracts were tested repeatedly, usually at a single concentration value rather than over a range of concentrations. 
TABLE 2

Response of Ileum Preparations to Extracts of Cardroom Dust and Pollution Particles

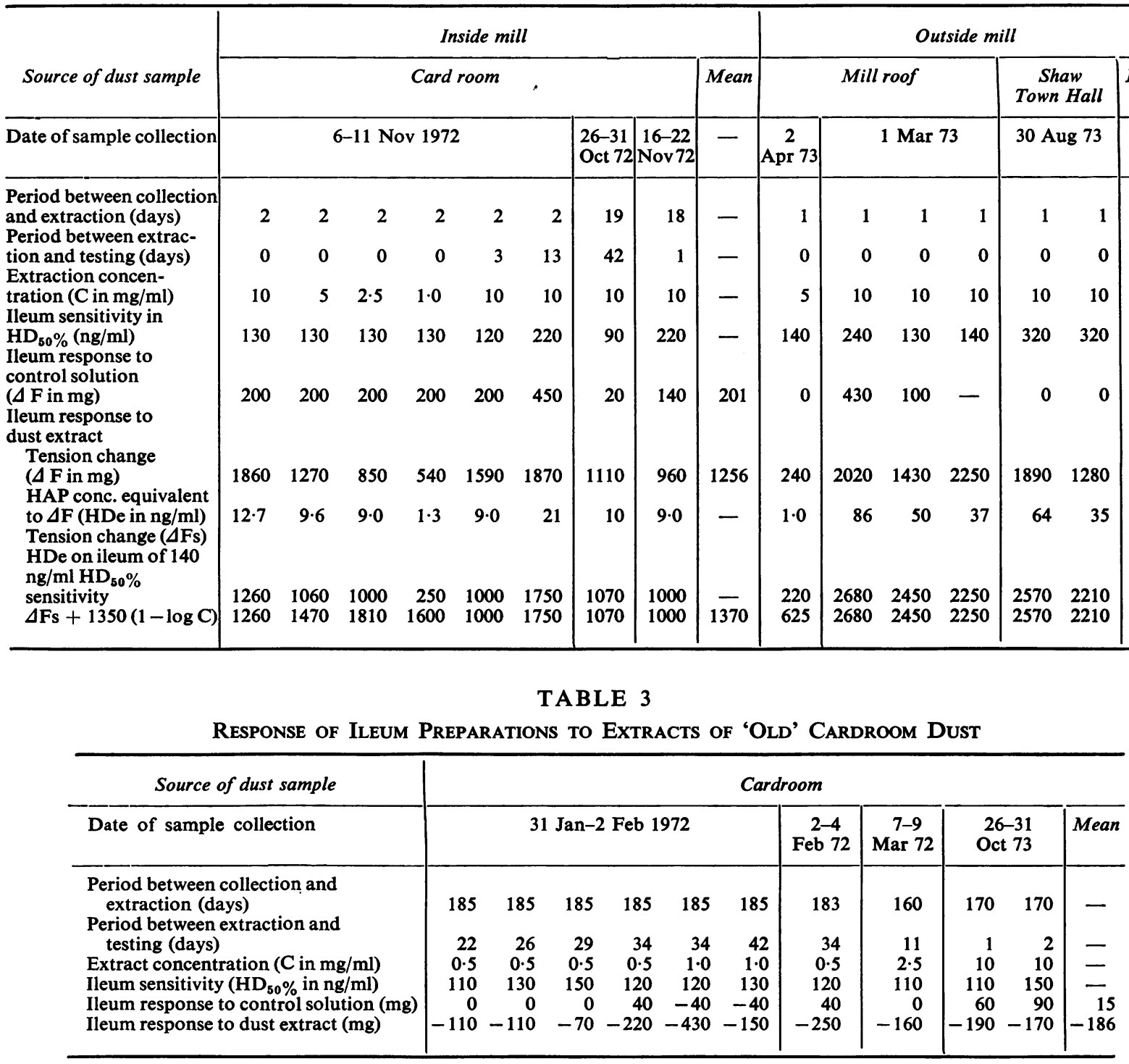

Ileum responses indicated that extracts of the aerosol polluting the Lancashire air caused the ileum to contract more than did the extracts of airborne dust collected in the cardroom of this particular mill. Considering the variabilities involved, the ileum response to the cardroom dust could have been brought about purely by ordinary air pollutants which constitute up to $20 \%$ of the airborne dust in the mills. Thus the ileum contraction brought about by extracts of cardroom dust may have had nothing to do with particles that derive from the cotton spinning process, and based on this a test to assess the capacity of the dust to cause byssinosis may not be possible. This conclusion is entirely consistent with the earlier findings of Berry et al. (1973).

It is interesting that samples of airborne dust which were left standing for several months before extraction and testing caused the ileum to relax rather than to contract. It points to the pit-falls of using in this or any other tests samples which are not freshly drawn from airborne dust. 
We thank Drs. R. W. Forster and J. R. Fozard of the Department of Pharmacology, University of Manchester for their helpful suggestions.

\section{References}

Berry, G., McKerrow, C. B., Molyneux, M. K. B., Rossiter, C. E., and Tombleson, J. B. L. (1973). A study of the acute and chronic changes in ventilatory capacity of workers in Lancashire cotton mills. British Journal of Industrial Medicine, 30, 25-36.

Davenport, A. and Paton, W. D. M. (1962). The pharmacological activity of extracts of cotton dust. British Journal of Industrial Medicine, 19, 19-32.

Department of Pharmacology, University of Edinburgh
(1970). Pharmacological Experiments on Isolated Preparations. Livingstone, Edinburgh.

Gaddum, J. H. (1953). The technique of superfusion. British Journal of Pharmacology and Chemotherapy, 8, 321.

Nicholls, P. J., (1962). Pharmacological action of cotton dust. British Journal of Industrial Medicine, 19, 33-41.

Received for publication 16 September 1974

Accepted for publication 6 November 1974

\section{The May (1975) Issue}

People and work: some contemporary issues Sylvia SHimmin

The purposes of occupational medicine P. A. B. RAFFLE

Circadian variation in physiological responses to exercise on a stationary bicycle ergometer $\quad$ C. T. M. DAvIES AND A. J. SARgeant

Carboxyhaemoglobin levels of smokers and non-smokers in the City of London C. M. CASTLEDEN AND P. V. COLE

A comparison of concentrations of lead in human tissues P. S. I. Barry

Effects of a single exposure to carbon disulphide on the rate of urea production and on plasma free fatty acid and glucose concentrations in the rat V. J. CUNNINGHAM

Dust exposure in manual flax processing in Egypt M. H. NoweIR, Y. M. El-SADIK, A. A. El-DaKhaKHN, AND H. A. Osman

Application of blood cadmium determination to industry using a punched disc technique A. A. CERNIK AND M. H.P.SAYERS

Notes and miscellanea

Myoglobinuria and renal failure in toluene poisoning E. REISIN, A. TEICHER, R. JAFFE, AND H. E. EliaHou

Recent progress in the study of occupational lung diseases in Romania B. Barhad, L. PILAT, AND D. TECULESCU

Book reviews

\section{Information section}

A number of copies are still available and may be obtained from the Publishing Manager, British Medical Association, Tavistock Square, London WC1H 9JR, price $£ 2 \cdot 50$; U.S.A. \$7.50). 